\title{
Unsteadiness of breathing in patients with hyperventilation syndrome and anxiety disorders
}

\author{
J.N. Han*, K. Stegen**, K. Simkens*, M. Cauberghs*, R. Schepers*, \\ O. Van den Bergh**, J. Clément*, K.P. Van de Woestijne*
}

Unsteadiness of breathing in patients with hyperventilation syndrome and anxiety disorders. J.N. Han, K. Stegen, K. Simkens, M. Cauberghs, R. Schepers, O. Van den Bergh, J. Clément, K.P. Van de Woestijne. @ERS Journals Ltd 1997.

ABSTRACT: The breathing pattern of 399 patients with hyperventilation syndrome (HVS) and/or with anxiety disorders and that of 347 normal controls was investigated during a $5 \mathrm{~min}$ period of quiet breathing and after a $3 \mathrm{~min}$ period of voluntary hyperventilation.

The diagnosis of HVS was based on the presence of several suggestive complaints occurring in the context of stress, and reproduced by voluntary hyperventilation. Organic diseases as a cause of the symptoms were excluded. The anxiety disorders were diagnosed by means of an abbreviated version of the Anxiety Disorders Interview Schedule (ADIS). There was a large overlap between the two diagnoses.

Simply breathing via a mouthpiece and pneumotachograph made end-tidal $\mathrm{CO}_{2}$ fractional concentration $\left(\mathrm{FET}, \mathrm{CO}_{2}\right)$ decrease progressively both in hyperventilators and in patients with anxiety disorders, but not in normals. At the start of the measurement the $\mathrm{FET}_{\mathrm{ET}} \mathrm{CO}_{2}$ was not different between patients and healthy subjects. In

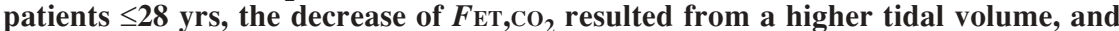
in patients $\geq 29$ years from an increase in frequency. After voluntary hyperventilation, the recovery of $\mathrm{FET}_{\mathrm{ET}} \mathrm{CO}_{2}$ was delayed in patients, due to a slower normalization of respiratory frequency in females and in older males, and of tidal volume in younger males, and also due to less frequent end-expiratory pauses. When breathing was recorded first by means of inductive plethysmography (Respitrace), the progressive decline of $\mathrm{FET}_{\mathrm{ETO}} \mathrm{CO}_{2}$ seen in patients was not observed: from the onset of the recording, $\mathrm{FET}_{\mathrm{ET}} \mathrm{CO}_{2}$ was reduced in patients. It did not change further when, immediately afterwards, the subject switched to mouthpiece breathing.

The finding that breathing through a mouthpiece induces hyperventilation in patients and that recovery of $\mathrm{FET}_{\mathrm{ET}} \mathrm{CO}_{2}$ is delayed after voluntary hyperventilation, suggests that the respiratory control system is less resistant to challenges (mouthpiece or voluntary hyperventilation) in those patients. On the other hand, the lower values of $F_{\mathrm{ET}}, \mathrm{CO}_{2}$ measured during recording by means of a Respitrace probably result from a challenge, prior to the recordings, induced by the fitting of the measuring device to the patient. This unsteadiness of breathing characterizes patients with hyperventilation syndrome and those with anxiety disorders, but is not sufficiently sensitive to be used for individual diagnosis.

Eur Respir J., 1997; 10: 167-176.
*Laboratory of Pneumology, U.Z. Gasthuisberg, Katholieke Universiteit Leuven, Leuven, Belgium. **Dept of Psychology, University of Leuven, Leuven, Belgium.

Correspondence: K.P. Van de Woestijne Laboratory of Pneumology U. Z. Gasthuisberg

Herestraat 49

B-3000 Leuven

Belgium

Keywords: Anxiety disorders breathing frequency end-tidal carbon dioxide hyperventilation syndrome tidal volume

Received: November 91995 Accepted after revision August 201996

Supported by the Research Council of the University of Leuven (grant OT/93/12).
Many so-called "psychosomatic" patients report various respiratory, cardiac, neurological and/or psychological complaints, which cannot be explained by a somatic disorder. Several labels have been used to classify these patients, the most frequently used being Da Costa syndrome [1], neurocirculatory asthenia [2], anxiety neurosis [3], functional cardiovascular disease [4], cardiac neurosis [5], or hyperventilation syndrome (HVS) [6]. The breathing pattern of these patients is often irregular. In 1935, CHRISTIE [7] described two different patterns: 1) a rapid shallow breathing, with irregularities of respiratory level, respiratory depth and rate typical of patients with anxiety neurosis; and 2) a characteristic "sighing respiration" leading, in severe cases, to paroxysmal hyperventilation. Similar patterns were observed in patients with so-called neurocirculatory asthenia [8], or with HVS $[9,10]$. In contrast to these descriptions emphasizing the irregular breathing pattern, GARSSEN and RIJKEN [11] described a regular, rapid and somewhat shallow breathing pattern, without sighs, met in about half of their HVS patients. ToBin et al. [12] observed that the very erratic breathing pattern recorded by means of respiratory inductive plethysmography in patients with "chronic anxiety state" became more regular when the patients were breathing on a mouthpiece, suggesting that taking in the mouthpiece and occluding the nose apparently masks the original irregular breathing pattern. Another characteristic of the breathing of the patients with HVS was described by HARDONK and BEUMER [13]: when the patients resumed spontaneous breathing after a period of voluntary hyperventilation, they did not decrease their ventilation to the 
control level as rapidly as healthy subjects [13-15]. In addition, periods of apnoea (lasting sometimes more than $12 \mathrm{~s}$ ) were observed following hyperventilation in normal control subjects, never in patients with HVS. On the basis of these observations, HARDONK and BEUMER [13] standardized a so-called hyperventilation provocation test (HVPT) as a tool for the diagnosis of HVS.

With the exception of the study by HARDONK and BEUMER [13], no systematic investigation of the breathing pattern of patients with HVS has so far been performed. The purpose of the present study was to determine how frequent the described breathing abnormalities are, and whether they can be used for diagnosis in a large group of patients. Breathing pattern was systematically measured by means of a pneumotachograph, and endtidal $\mathrm{CO}_{2}$ fractional concentration $\left(F \mathrm{ET}, \mathrm{CO}_{2}\right)$ was recorded at rest and during recovery from a $3 \mathrm{~min}$ period of voluntary hyperventilation. To all patients, who were referred because they presented complaints which were not explained by an organic disease and which were suspected of being related to hyperventilation, the diagnostic criteria both of HVS and of anxiety disorders, were applied according to the Diagnostic and Statistical Manual of Mental Disorders (DSM-III-R) [16]. This made it possible to verify whether there was a difference in breathing behaviour between HVS and anxiety disorders (Study One). In an additional group (Study Two) of healthy subjects and patients, the influence of recording technique on the breathing pattern was investigated: ventilation at rest was measured successively by means of inductive plethysmography and pneumotachography.

\section{Methods}

\section{Study one}

Subjects. Two hundred and one naive normal subjects (96 females and 105 males) and 308 patients (163 females and 145 males) with HVS and/or anxiety disorders were studied. The age span was 19-62 years. Among the patients, 232 were suffering from HVS (127 females and 105 males), 239 from anxiety disorders (132 females and 107 males), and 163 from both. The occurrence of anxiety disorders in patients with HVS was $72 \%$ in females and $62 \%$ in males. Sixty five percent of female and $58 \%$ of male patients with anxiety disorders were at the same time diagnosed as HVS. Another group of 90 patients (60 females and 30 males) with HVS but without anxiety disorders, and of 43 patients (27 females and 16 males) with anxiety disorders without HVS was recruited. In total, there were 159 patients with HVS but without anxiety disorders (91 females and 68 males), and 119 patients with anxiety disorders without HVS (63 females and 56 males).

After excluding organic diseases as a cause of the symptoms, HVS was diagnosed on the basis of several suggestive complaints occurring in the context of stress, as observed in a semistructured interview, and the reproduction of the most important complaints by the HVPT. The Nijmegen Questionnaire was used as confirmatory evidence for the diagnosis [17]. Most patients (187 out of 232) presented a score $\geq 23$ on this questionnaire, which is considered as indicative of the HVS [17].
The occurrence of anxiety disorders was detected by means of an abbreviated version of the ADIS [18], allowing diagnosis of the various categories of anxiety disorders according to the criteria of the DSM-III-R (panic disorder, post-traumatic stress disorder, generalized anxiety disorder, anxiety disorder not otherwise specified, agoraphobia, and social phobia). No distinction was made between subjects presenting one or more variants of these disorders. This questionnaire was also used for screening for somatoform disorders, for depression and dysthymia.

The anxiety level of the healthy subjects and patients was evaluated using the state and trait versions of the Zelfbeoordelingsvragenlijst (ZBV-DY1, ZBV-DY2) [19], which is the Dutch adapted version of the State-Trait Anxiety Inventory (STAI) of SPIELBERGER et al. [20].

Methods. A pneumotachograph (Fleisch No. 2, Switzerland), connected to a differential transducer (Validyne $\mathrm{MP} 45, \pm 2 \mathrm{cmH}_{2} \mathrm{O}$ ) and infra-red $\mathrm{CO}_{2}$ monitor (Capnograph, POET I; Criticare, USA) were used for respiratory recordings. The dead space of the pneumotachograph and mouthpiece was $40 \mathrm{~mL}$. The Capnograph was connected to the mouthpiece. The subjects sat on a comfortable chair in a quiet room. The following situations were studied: ventilation at rest during $5 \mathrm{~min}$; and $3 \mathrm{~min}$ voluntary hyperventilation followed by a $5 \mathrm{~min}$ period of recovery. During the experiment, instructions were reduced to a minimum. At the beginning of the rest period, the subject was asked to breathe quietly. Subsequently, he was requested to perform voluntary hyperventilation as deeply as possible at a rhythm of 60 breaths $\cdot \mathrm{min}^{-1}$. The frequency was indicated by a metronome and the subject was coached during the whole period of hyperventilation. At the end of the third minute of voluntary hyperventilation, the subject was notified once that he should resume quiet breathing.

One hundred and thirty four patients (65 females and 69 males) with HVS (with or without anxiety disorders) were matched to 134 normal subjects for sex and age, and 138 patients (65 females and 73 males) with anxiety disorders (with or without HVS) were matched to 138 normal subjects for sex and age.

Similarly, a comparison was performed between the patients with HVS but without anxiety disorders and those with anxiety disorders without HVS. Younger ( $\leq 28$ yrs) and older ( $\geq 29 \mathrm{yrs}$ ) patients, males and females, were compared separately, though at these smaller samples a perfect matching for sex and age was not possible.

Data analysis. The respiratory signals and $F \mathrm{ET}, \mathrm{CO}_{2}$ measured during $5 \mathrm{~min}$ of rest and during the $5 \mathrm{~min}$ of recovery following hyperventilation were analysed. The data were first plotted as a function of time to search for gross artefacts (coughs, interruptions). The latter were deleted from the data file. Respiratory signals were then treated breath-by-breath using software which separated regular breathing from breathing irregularities. After synchronizing with $F \mathrm{ET}, \mathrm{CO}_{2}$, the following primary parameters were obtained for each breath: inspiratory time $(t \mathrm{I})$, inspiratory tidal volume $(V \mathrm{~T}, \mathrm{I})$, expiratory time $(t \mathrm{E})$, expiratory tidal volume $(V \mathrm{~T}, \mathrm{E})$, and $\mathrm{F}_{\mathrm{ET}}, \mathrm{CO}_{2}$. Since the mean value of $V_{\mathrm{T}, \mathrm{I}}$ was not different from that of $V_{\mathrm{T}, \mathrm{E}}$, the 
latter was deleted from the analysis. In the remainder of the present paper, $V_{\mathrm{T}}$ is used as a symbol for $V_{\mathrm{T}, \mathrm{I}}$.

For each period in each subject the following were calculated: the mean value, linear change of respiratory parameter as a function of time (also named "slope"), and residual standard deviation of the regression as a function of time (square root of mean square error: $\left.\mathrm{MSE}^{1 / 2}\right)$ for each primary parameter $\left(t \mathrm{I}, t \mathrm{E}, V_{\mathrm{T}}, F_{\left.\mathrm{ET}, \mathrm{CO}_{2}\right)}\right.$ and for inspiratory flow rate $(V \mathrm{~T} / t \mathrm{I})$. Systematically a linear and a quadratic regression were calculated, when the latter gave a better fit of the data $(\mathrm{p}<0.20)$ it was used to calculate. Slope and residual standard deviation were determined to estimate the unsteadiness of the breathing pattern and the between-breath variability of the different parameters.

Breathing irregularities were not included for these calculations and were treated separately. Among breathing irregularities, end-expiratory pauses occurred fairly often and were investigated. The criteria for a pause are that it has a duration of at least $0.5 \mathrm{~s}$ with a flow of less than $0.05 \mathrm{~L} \cdot \mathrm{s}^{-1}$. The absolute number of pauses was counted separately in the two experimental situations: rest and recovery from HVPT. Sighs were defined as a deep breath, the volume of which exceeds three times the standard deviation of $V_{\mathrm{T}}$; it should be larger than two times the average $V_{\mathrm{T}}$.

\section{Study two}

Subjects. Another group of 91 patients (44 females and 47 males) and 146 healthy subjects, aged 18-63 yrs, were studied. Seventy of the 91 patients were diagnosed as HVS, and 55 out of 91 as anxiety disorders, showing a large diagnostic overlap; 65 patients (28 females and 37 males) with HVS were matched to 65 healthy subjects for sex and age, and 48 patients (24 females and 24 males) with anxiety disorders to 48 healthy subjects.

Methods. Breathing was recorded with a respiratory inductive plethysmograph (Model 150; Respitrace Corp., NY, USA). The Capnograph was connected to the entrance of a nostril.

The coils of the Respitrace were stuck to the skin, one around the rib cage under the axilla and the other on the abdomen above the pelvis. The Respitrace was operated in alternating current. This mode was used because of its better long-term stability [21]. Breathing was recorded in the sitting position during $5 \mathrm{~min}$. This was followed, without interruption, by a 5 min period during which ventilation was measured both with Respitrace and with the pneumotachograph. Interruptions were avoided, so that not more than one or two breaths were lost between successive recordings. The Respitrace was calibrated over the $5 \mathrm{~min}$ period during which breathing was simultaneously recorded by pneumotachograph and Respitrace. Respiratory signals (tidal volume, rib cage and abdominal signals) were sampled at a rate of 20 signals $\cdot \mathrm{s}^{-1}$. The coefficients of rib cage and abdominal signals over a period of $5 \mathrm{~min}$ were derived from multiple linear regression (MLR) [22]. The accuracy of this method for estimation of tidal volume $(V \mathrm{~T})$ was checked by comparison with the mean $V_{\mathrm{T}}$ value obtained simultaneously from the pneumotachograph. The data were accepted only when the agreement was better than $80 \%$. For both 5 min periods, the analysis of the breathing pattern was performed on reconstructed ventilation from Respitrace.

\section{Statistical treatment}

In Study One, a multivariate analysis of variance (MANOVA) was used on all breathing variables with a $2 \times 2 \times 2$ design (gender (males and females), age ( $\leq 28$ and $\geq 29$ yrs), group (patients and healthy subjects)). Because the highest order interaction gender $\times$ age $\times$ group and the interaction age $\times$ group in females were at the limit of statistical significance $(p=0.06)$, gender, age and group were separated for further analyses. The age separation at 28 yrs was justified by a change in breathing pattern in healthy subjects past that age, i.e. a marked decrease of frequency of end-expiratory pauses, particularly in males (fig. 1). Student's t-test was used to compare unpaired samples of healthy subjects and patients, separately in males and females, young and old subjects. Chi-squared test (or binomial distribution test) made it possible to compare the frequency of the irregularities of the healthy subjects with that of the patients. A discriminant analysis was employed to investigate which combination of

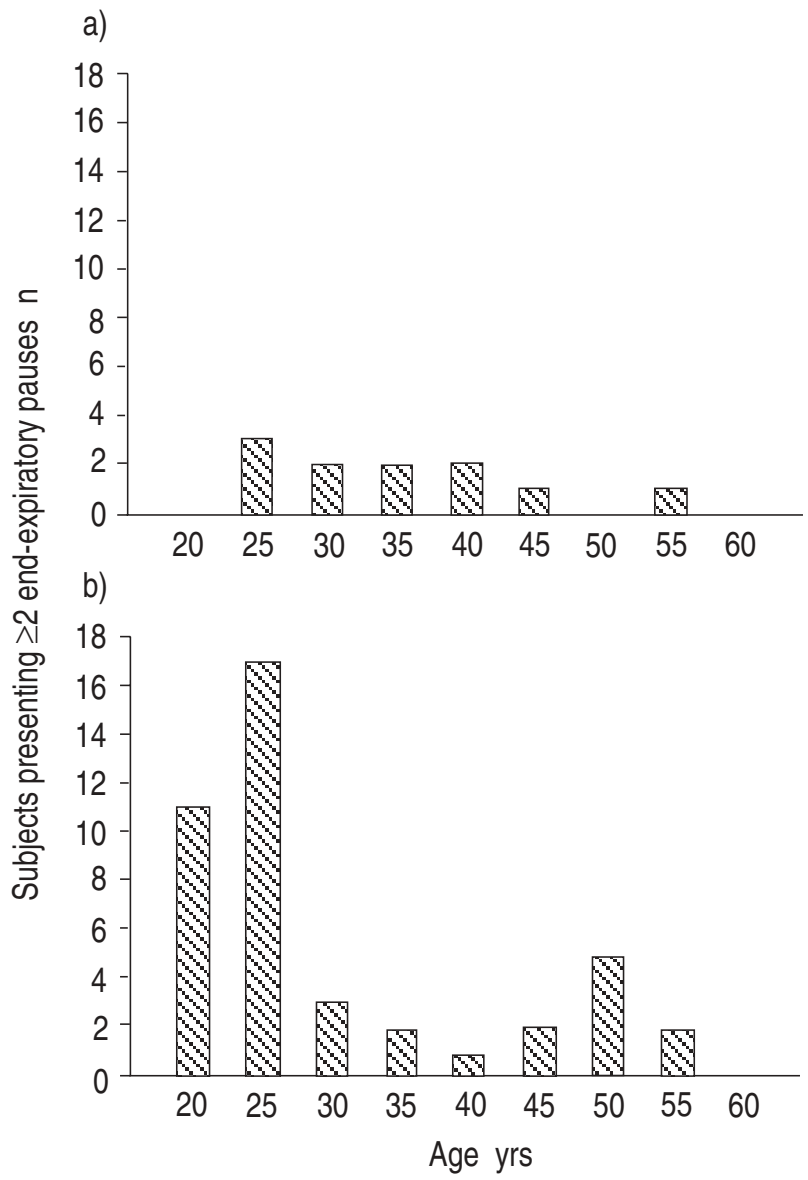

Fig. 1. - The occurrence of end-expiratory pauses as a function of age: a) in healthy males; and b) in 105 male hyperventilators. Each bar corresponds to a 5 year age period. The midpoint of age is indicated on the scale. Compared to only 11 out of 105 hyperventilators, 43 out of 105 healthy males presented two or more end-expiratory pauses in the second to fifth minutes of recovery following a hyperventilation provocation test (HVPT); most of them were younger than 28 yrs of age. 
the respiratory parameters (including irregularities) best separated healthy subjects from patients.

In Study Two, similar statistical techniques were used, except that a $2 \times 2 \times 2 \times 2$ design was used for the MANOVA (gender, age, group and recording technique (Respitrace and mouthpiece)), among which the first three were between-comparisons and the last was a within-comparison. The fourth order interaction (gender $\times$ age $\times$ group $\times$ recording) was not significant $(\mathrm{p}=0.99)$. Among the third order interactions, only gender $\times$ age $\times$ group attained a probability level close to statistical significance $(\mathrm{p}=0.08)$. Therefore, separate analyses were made of the influence of gender, age and group on the recording technique.

\section{Results}

\section{Biological and psychological characteristics}

Table 1 lists some biological and psychological features of matched healthy subjects and patients in Study One. Because of the influence of age on breathing pattern, younger and older subjects were considered separately. The scores of STAI, and the scores of the Nijmegen Questionnaire (table 1) were significantly higher both for males and females in patients with HVS and anxiety disorders than in matched healthy subjects. Similar differences were observed in Study Two for the scores of STAI and the Nijmegen Questionnaire. In both studies, similar scores were obtained in patients with HVS and with anxiety disorders. This is not unexpected, since there was a large overlap between the two groups. However, when patients with HVS only (without anxiety disorders) were compared to patients with anxiety disorders without HVS, differences showed up: whereas the scores of STAI-state were similar (on average: 46.9 vs 47.1), those of STAI-trait were slightly less (45.5 vs 50.2; $\mathrm{p}=$ 0.0008 ), and the scores of the Nijmegen Questionnaire were markedly higher (27.8 vs 19.5 ; $\mathrm{p}=0.00001)$ in the patients with isolated HVS.
Study One: breathing pattern at rest and following hyperventilation

\section{Hyperventilation syndrome}

Subjects aged $\leq 28$ yrs. During rest (fig. 2), mean values of $F_{\mathrm{ET}}, \mathrm{CO}_{2}$ were lower in HVS patients, in contrast to healthy subjects (females 4.43 vs $4.99 \%$, $\mathrm{p}=0.003$; males 4.96 vs $5.35 \%, \mathrm{p}=0.01)$. This resulted from a highly significant (females $\mathrm{p}=0.0002$; males $\mathrm{p}=0.007$ ) decrease of $F_{\mathrm{ET}, \mathrm{CO}_{2}}$ as a function of time both in male and female hyperventilators compared with healthy subjects (females -0.0020 vs $-0.0003 \% \cdot \mathrm{s}^{-1}$; males -0.0011 vs $\left.-0.0001 \% \cdot \mathrm{s}^{-1}\right)$. The $F \mathrm{ET}, \mathrm{CO}_{2}$ value of the first breath (time 0 ) was not significantly different in the two groups (males $\mathrm{p}=0.18$; females $\mathrm{p}=0.44)$. $V_{\mathrm{T}}$ tended to be higher in hyperventilators than in normal subjects. This difference was significant only in males $(\mathrm{p}=0.03) . V_{\mathrm{T}} / t \mathrm{I}$ was significantly higher in both female and male hyperventilators $(p<0.05)$. Respiratory frequency was similar (15.1 vs 14.6 breaths $\cdot \mathrm{min}^{-1}$ in patients and healthy subjects, respectively, both males and females).

After HVPT, a statistically significant delay in recuperation of $\mathrm{FET}_{\mathrm{ET}} \mathrm{CO}_{2}$ was observed both in male and female hyperventilators (slope of $F \mathrm{ET}, \mathrm{CO}_{2}: 0.0026$ vs $0.0040 \% \cdot \mathrm{s}^{-1}$ in females, $\mathrm{p}=0.02,0.0028$ vs $0.0045 \% \cdot \mathrm{s}^{-1}$ in males, $\mathrm{p}=$ 0.002 ) (fig. 3). In female hyperventilators, this retarded increase of $F \mathrm{ET}, \mathrm{CO}_{2}$ was associated with a delay in normalization of respiratory frequency (mean frequency: 20.4 vs 15.8 breaths $\cdot \mathrm{min}^{-1}$ in normals $(\mathrm{p}=0.02)$, due to a lower value of $t \mathrm{I}(\mathrm{p}=0.01))$, while in male hyperventilators it resulted from a less rapid decrease of tidal volume $(\mathrm{p}=$ $0.04)$. The within-subject variability $\left(\mathrm{MSE}^{1} / 2\right)$ of $t \mathrm{I}$ was less $(\mathrm{p}=0.03)$ both in male and female hyperventilators. $F \mathrm{ET}_{\text {, }} \mathrm{CO}_{2}$ of the first breath (time 0 ) following HVPT was not significantly different in the healthy subjects and the hyperventilators (males $\mathrm{p}=0.61$; females $\mathrm{p}=0.71$ ).

Subjects aged $\geq 29$ yrs. During rest, ventilation differed in hyperventilators mainly because of a higher respiratory

Table 1. - Biological characteristics and level of anxiety (STAI) and number of complaints (Nijmegen Questionnaire) of patients with HVS and anxiety disorders and matched normal subjects.

\begin{tabular}{|c|c|c|c|c|c|c|c|}
\hline $\begin{array}{l}\text { Age } \\
\text { yrs }\end{array}$ & Sex & Group & $\begin{array}{c}\mathrm{Ss} \\
\mathrm{n}\end{array}$ & $\begin{array}{l}\mathrm{Age}^{\#} \\
\text { yrs }\end{array}$ & STAI-State ${ }^{\ddagger}$ & STAI-Trait & $\begin{array}{c}\text { Nijmegen } \\
\text { Questionnaire }\end{array}$ \\
\hline \multirow[t]{8}{*}{$\leq 28$} & \multirow{2}{*}{$\mathrm{F}$} & $\mathrm{HV}$ & 23 & $24(20-28)$ & $51.2 \pm 12.7 * * *$ & $50.1 \pm 11.6^{* *}$ & $30.8 \pm 8.9 * * *$ \\
\hline & & $\mathrm{N}$ & 23 & $24(21-28)$ & $37.3 \pm 11.1$ & $38.8 \pm 10.2$ & $13.5 \pm 7.0$ \\
\hline & \multirow{2}{*}{ M } & HV & 27 & $24(19-28)$ & $51.4 \pm 14.2 * * *$ & $52.6 \pm 14.3 * * *$ & $29.9 \pm 10.3 * * *$ \\
\hline & & $\mathrm{N}$ & 27 & $24(20-28)$ & $30.4 \pm 8.4$ & $32.3 \pm 8.1$ & $7.6 \pm 5.6$ \\
\hline & \multirow{2}{*}{$\mathrm{F}$} & $\mathrm{AD}$ & 20 & $24(21-28)$ & $50.8 \pm 13.2 * *$ & $51.4 \pm 10.7 * *$ & $29.8 \pm 10.6$ *** \\
\hline & & $\mathrm{N}$ & 20 & $24(21-28)$ & $38.4 \pm 11.6$ & $39.6 \pm 10.6$ & $13.4 \pm 7.6$ \\
\hline & \multirow{2}{*}{ M } & $\mathrm{AD}$ & 25 & $24(20-28)$ & $53.1 \pm 13.0 * * *$ & $56.2 \pm 11.8 * * *$ & $29.6 \pm 10.8 * * *$ \\
\hline & & $\mathrm{N}$ & 25 & $24(20-28)$ & $31.0 \pm 9.0$ & $32.6 \pm 8.2$ & $7.1 \pm 5.1$ \\
\hline \multirow{8}{*}{$\geq 29$} & \multirow{2}{*}{$\mathrm{F}$} & HV & 42 & $42(29-59)$ & $53.5 \pm 11.7 * * *$ & $53.7 \pm 12.2 * * *$ & $32.1 \pm 11.4 * * *$ \\
\hline & & $\mathrm{N}$ & 42 & $42(29-60)$ & $37.8 \pm 9.1$ & $38.6 \pm 9.8$ & $12.0 \pm 7.0$ \\
\hline & \multirow{2}{*}{ M } & HV & 42 & $42(29-61)$ & $50.5 \pm 11.5 * * *$ & $49.6 \pm 10.8 * * *$ & $30.2 \pm 9.7 * * *$ \\
\hline & & $\mathrm{N}$ & 42 & $42(29-61)$ & $32.8 \pm 9.6$ & $33.9 \pm 10.0$ & $8.1 \pm 6.4$ \\
\hline & \multirow{2}{*}{$\mathrm{F}$} & $\mathrm{AD}$ & 45 & $43(29-61)$ & $53.6 \pm 10.8 * * *$ & $55.5 \pm 12.2 * * *$ & $29.3 \pm 11.1 * * *$ \\
\hline & & $\mathrm{N}$ & 45 & $43(29-62)$ & $37.3 \pm 9.2$ & $38.1 \pm 9.8$ & $11.6 \pm 6.9$ \\
\hline & \multirow{2}{*}{ M } & $\mathrm{AD}$ & 48 & $43(29-61)$ & $49.1 \pm 13.1 * * *$ & $48.8 \pm 11.4 * * *$ & $23.6 \pm 9.6 * * *$ \\
\hline & & $\mathrm{N}$ & 48 & $43(29-61)$ & $33.4 \pm 10.8$ & $34.4 \pm 9.8$ & $8.0 \pm 6.2$ \\
\hline
\end{tabular}

\#: mean and range in parenthesis; $\$$ : mean \pm sD; F: female; M: male; N: normal subjects; HV: hyperventilators; AD: patients with anxiety disorders; Ss: subjects; STAI: State-Trait Anxiety Inventory; HVS: hyperventilation syndrome. ${ }^{* *}: \mathrm{p}<0.01 ; * * *: \mathrm{p}<0.001$, compared to normal subjects of the same gender. 

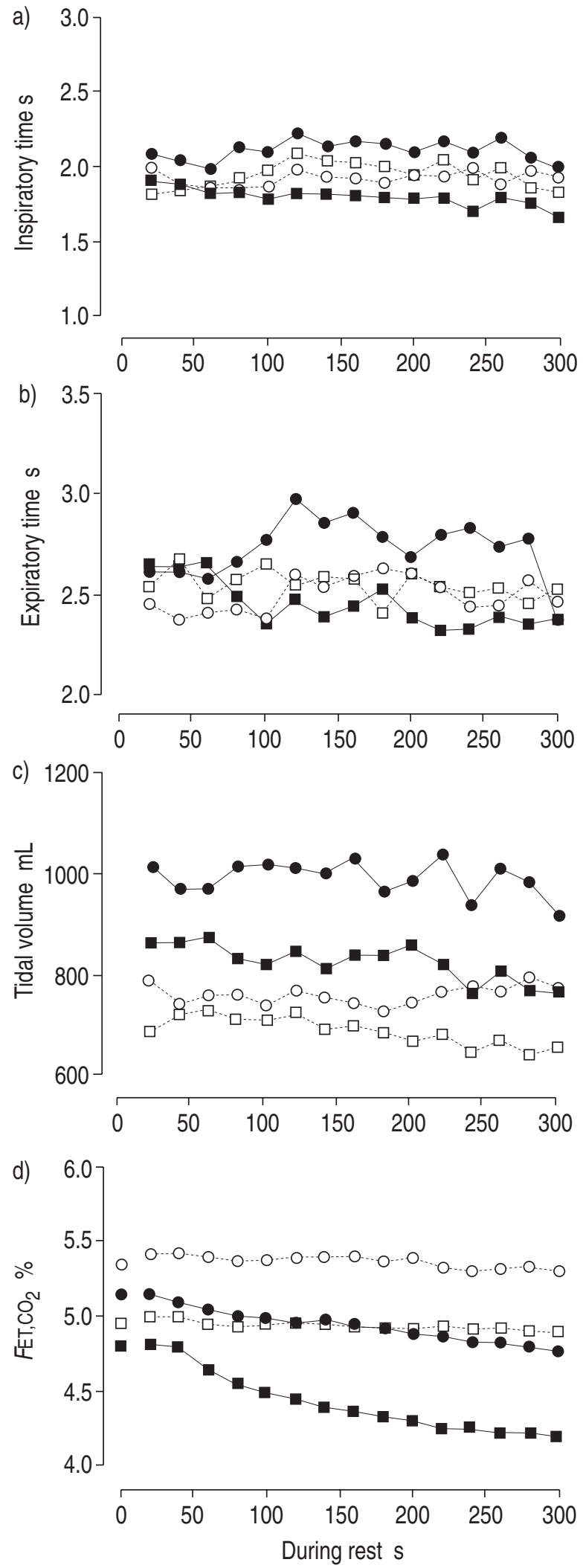

Fig. 2. - Mean values of: a) inspiratory time $(t \mathrm{I})$; b) expiratory time $(t \mathrm{E})$; c) tidal volume $\left(V_{\mathrm{T}}\right)$; and $\left.\mathrm{d}\right)$ end-tidal $\mathrm{CO}_{2}$ fractional concentration $\left(F_{\mathrm{ET}}, \mathrm{CO}_{2}\right)$ in healthy subjects (open symbols) and hyperventilators (solid symbols), aged $20-28$ yrs, during a 5 min rest period. Females are indicated by squares and males by circles. Each point corresponds to the mean of a $20 \mathrm{~s}$ period, except for the value of $\mathrm{FET}_{\mathrm{ET}} \mathrm{CO}_{2}$ at time 0 (first recorded breath). For the sake of clarity, standard deviations are not shown.
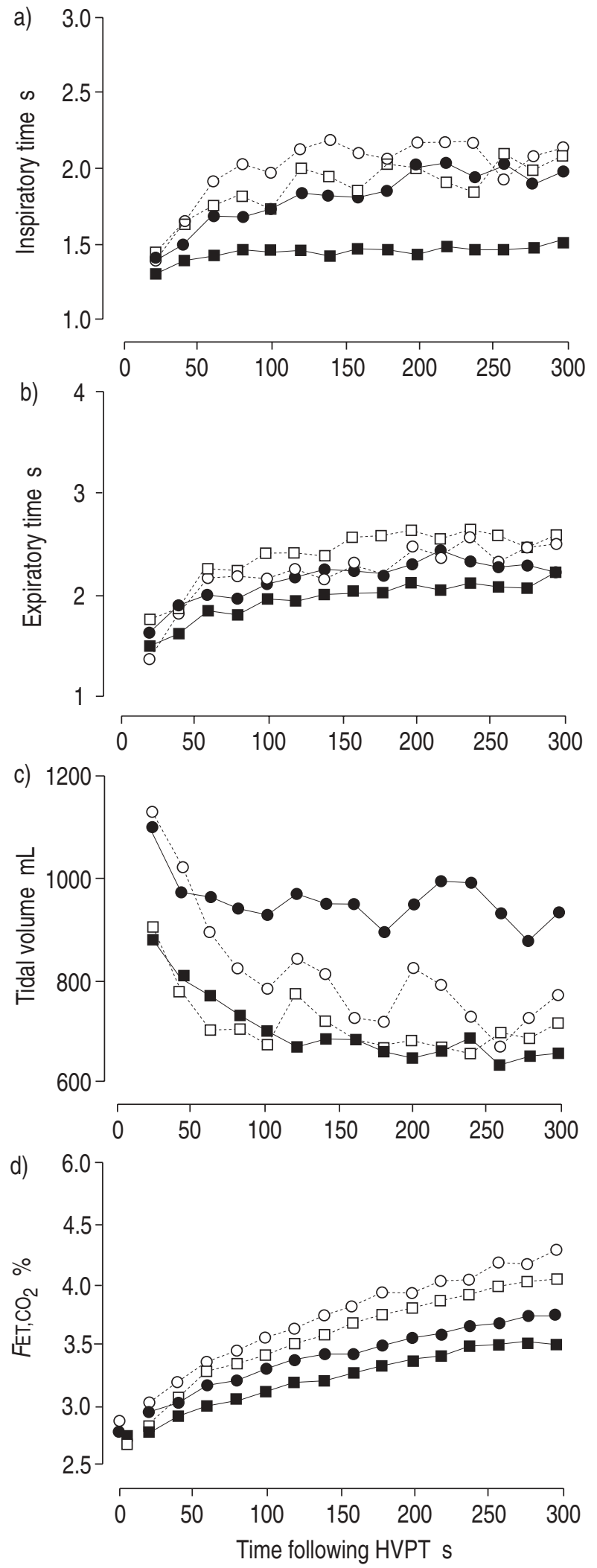

Fig. 3. - Mean values of: a) inspiratory time $(t \mathrm{I})$; b) expiratory time $(t \mathrm{E})$; c) tidal volume $\left(V_{\mathrm{T}}\right)$; and d) end-tidal $\mathrm{CO}_{2}$ fractional concentration $\left(F \mathrm{ET}, \mathrm{CO}_{2}\right)$ in healthy subjects (open symbols) and hyperventilators (solid symbols), aged 20-28 yrs, during a $5 \mathrm{~min}$ recovery period following hyperventilation provocation test. Females are indicated by squares and males by circles. Each point corresponds to the mean of a $20 \mathrm{~s}$ period, except for the value of $\mathrm{F}_{\mathrm{ET}, \mathrm{CO}_{2}}$ at time 0 (first recorded breath). For the sake of clarity, standard deviations are not shown. 
frequency (both $t$ and $t \mathrm{E}$ ), which was highly significant in females (18.1 vs 14.0 breaths. $\mathrm{min}^{-1}$ in healthy females; $\mathrm{p}=0.0001)$ and of borderline significance $(\mathrm{p}=0.05)$ in males (fig. 4). The mean values of $F_{\mathrm{ET}, \mathrm{CO}_{2}}$ tended to be lower and slope more negative in HVS patients both for males and females, but in contrast to younger subjects the differences did not reach statistical significance, because the slope of $F \mathrm{ET}, \mathrm{CO}_{2}$ was also (slightly) negative in healthy subjects. $F \mathrm{ET}, \mathrm{CO}_{2}$ values of the first breath (time 0 ) in the two groups were similar (males $p=0.34$; females $\mathrm{p}=0.85$ ). The within-subject variability of $F \mathrm{ET}, \mathrm{CO}_{2}$ was less in male hyperventilators than in healthy subjects $(p=0.008)$, but not in females.

After HVPT, mean values of $F_{\mathrm{ET}, \mathrm{CO}_{2}}$ were less in HVS patients, both males $(p=0.01)$ and females $(p=$ 0.02 ). Furthermore, in hyperventilators the recuperation of $F \mathrm{ET}, \mathrm{CO}_{2}$ was delayed, significantly so in male hyperventilators $(p=0.007)$. The values at time 0 were similar (males $\mathrm{p}=0.59$; females $\mathrm{p}=0.25$ ). The retarded increase of $F \mathrm{ET}, \mathrm{CO}_{2}$ resulted from higher breathing frequency in males: 18.2 vs 14.8 breaths $\cdot \mathrm{min}^{-1}$ in normal subjects $(\mathrm{p}=$ 001 , primarily because of a decrease of $t \mathrm{E}$ ), and females: 21.4 vs 16.7 breaths $\cdot \min ^{-1}$ ( $\mathrm{p}=0.0005$, due to a decrease of both $t \mathrm{I}$ and $t \mathrm{E}$ ) (fig. 5). The within-subject variability of $t \mathrm{I}, t \mathrm{E}$, and $F \mathrm{ET}, \mathrm{CO}_{2}$ tended to be less in hyperventilators (significantly for $t \mathrm{I}$ and $t \mathrm{E}$ in females, $\mathrm{p}<0.05$, for $F \mathrm{ET}, \mathrm{CO}_{2}$ in males, $\mathrm{p}=0.02$ ).

Anxiety disorders. Comparison of breathing patterns (at rest and following HVPT) between healthy subjects and patients with anxiety disorders yielded similar differences: progressive decline of $F \mathrm{ET}, \mathrm{CO}_{2}$ at rest and retarded increase of $F$ ET, $\mathrm{CO}_{2}$ after HVPT in patients $\leq 28 \mathrm{yrs}$; higher respiratory frequency at rest (both for $t \mathrm{I}$ and $t \mathrm{E}$, in males and females) and slow recovery of $F \mathrm{ET}, \mathrm{CO}_{2}$ after HVPT in patients $\geq 29$ yrs.

HVS only versus anxiety disorders only. To determine possible differences between the two conditions, we compared a number of subjects with isolated HVS without anxiety disorders, and subjects with anxiety disorders without HVS. Only minimal differences, a few with borderline statistical significance, were noticed.

Irregularities. Sighs were rare during breathing through a mouthpiece, in patients as well as in healthy subjects. Similarly, the number of end-expiratory pauses was small in hyperventilators and in healthy subjects during rest, but increased markedly in the healthy subjects during recovery from HVPT. Dividing the subjects into those with one pause or less, and those with more than one pause in the second to the fifth minute of the recovery period, showed that there were significantly $(\mathrm{p}<0.05)$ more normal subjects, particularly in subjects $\leq 28$ yrs old, with two or more pauses following HVPT than hyperventilators and patients with anxiety disorders.

Discriminant analysis of respiratory indices. To investigate which combination of respiratory variables best separated healthy subjects from hyperventilators or patients with anxiety disorders, with a minimal number of variables, a discriminant analysis was performed. Because breathing pattern changes with ageing, age and its
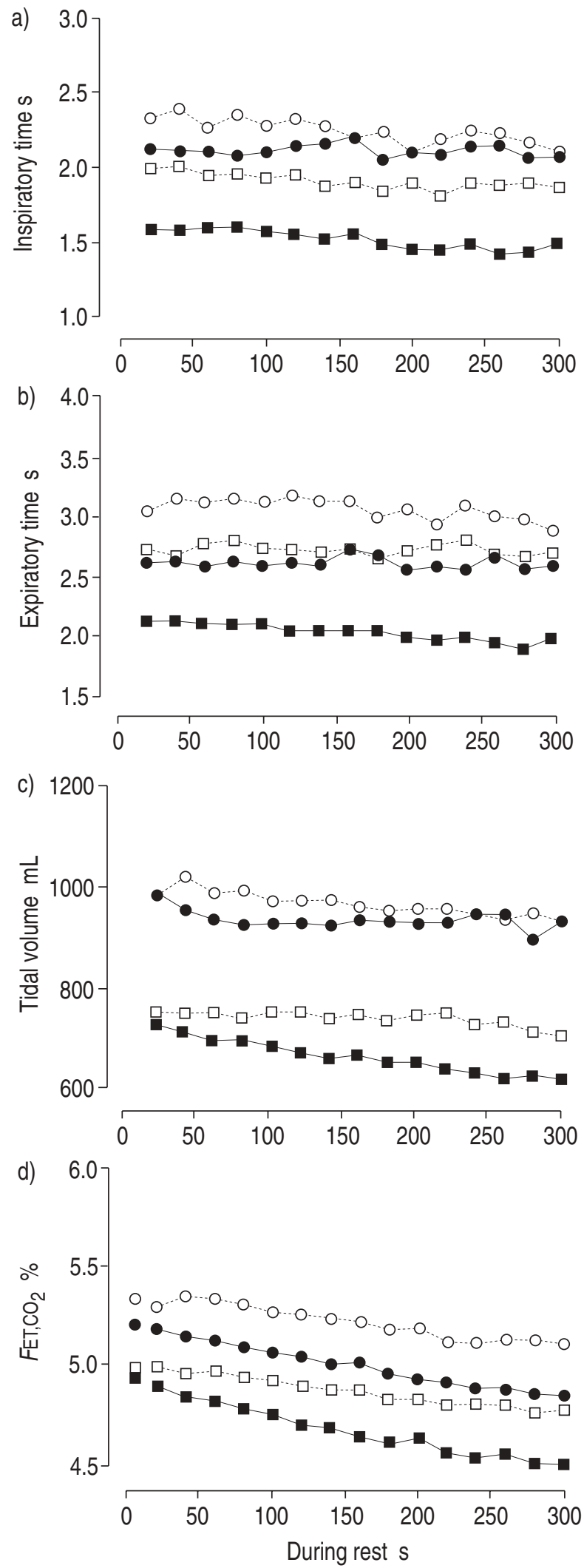

Fig. 4. - Mean course of: a) inspiratory time $(t \mathrm{I})$; b) expiratory time $(t \mathrm{E})$; c) tidal volume $\left(V_{\mathrm{T}}\right)$; and d) end-tidal $\mathrm{CO}_{2}$ fractional concentration $\left(F \mathrm{ET}, \mathrm{CO}_{2}\right)$ in healthy subjects (open symbols) and hyperventilators (solid symbols), aged 29-60 yrs, during a 5 min rest period. Females are indicated by squares and males by circles. Each point corresponds to the mean of a $20 \mathrm{~s}$ period, except for the value of $F \mathrm{ET}, \mathrm{CO}_{2}$ at time 0 (first recorded breath). For the sake of clarity, standard deviations are not shown. 

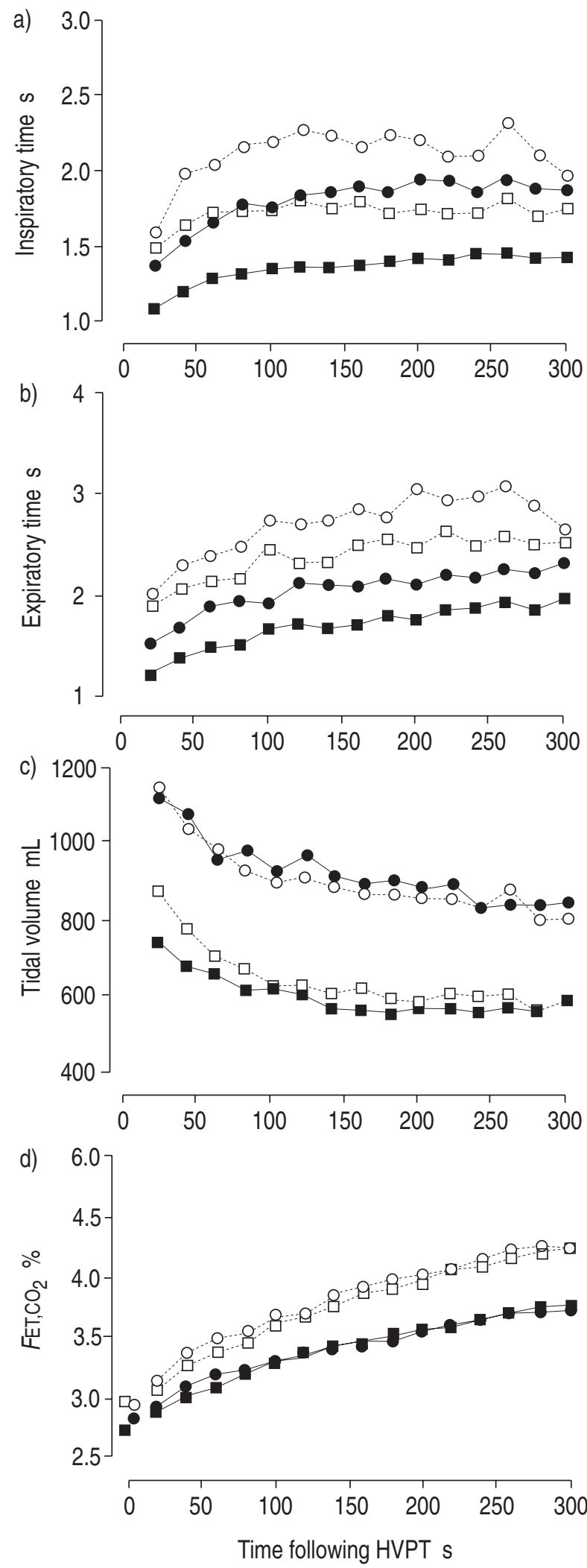

Study Two: breathing pattern with Respitrace and mouthpiece

Breathing with Respitrace. During breathing with Respitrace, patients differed from normal subjects mainly by the mean value of $\mathrm{FET}, \mathrm{CO}_{2}$, which was significantly lower in hyperventilators, both for males and females $(p<0.001)$ (fig. 6), and in patients with anxiety disorders (only females: $\mathrm{p}=0.005$ ). In addition, the $F \mathrm{ET}, \mathrm{CO}_{2}$ of the first breath with Respitrace (time 0) in patients with HVS and anxiety disorders was significantly lower than in normals $(\mathrm{p}<$ 0.001 in hyperventilators both for males and females; $\mathrm{p}<0.05$ in patients with anxiety disorders both for males and females). The other respiratory variables did not differ significantly.

Separating the subjects into younger $(\leq 28 \mathrm{yrs})$ and older ( $\geq 29 \mathrm{yrs}$ ) individuals yielded similar results, except

Table 2. - Discriminant analysis on respiratory parameters

\begin{tabular}{|c|c|c|}
\hline Group & Age $\leq 28$ yrs & Age $\geq 29$ yrs \\
\hline $\mathbf{N} \odot-\mathrm{HV} \odot$ & $\begin{array}{l}\mathrm{R}^{2}=0.29(\mathrm{p}=0.0007) \\
\text { Slope } \mathrm{CO}_{2} \text { (rest) } \\
\text { Pexpin (HVPT) }\end{array}$ & $\begin{array}{l}\mathrm{R}^{2}=0.32(\mathrm{p}=0.0001) \\
\text { Mean } t \text { ( }(\mathrm{rest}) \\
\text { Pexpin }(\mathrm{HVPT}) \\
\text { Mean } \mathrm{CO}_{2}(\mathrm{HVPT})\end{array}$ \\
\hline $\mathbf{N}+-\mathrm{AD} \uparrow$ & $\begin{array}{l}\mathrm{R}^{2}=0.30(\mathrm{p}=0.0013) \\
\text { Slope } \mathrm{CO}_{2} \text { (rest) } \\
\text { Pexpin }(\mathrm{HVPT})\end{array}$ & $\begin{array}{l}\mathrm{R}^{2}=0.22(\mathrm{p}=0.0001) \\
\text { Mean } t \text { I (rest) } \\
\text { Pexpin (HVPT) } \\
\text { Mean } \mathrm{CO}_{2}(\mathrm{HVPT})\end{array}$ \\
\hline $\mathrm{N} \sigma^{7}-\mathrm{HVO}$ & $\begin{array}{l}\mathrm{R}^{2}=0.26(\mathrm{p}=0.0004) \\
\text { Slope } \mathrm{CO}_{2} \text { (rest) } \\
\text { Pexpin }(\mathrm{HVPT})\end{array}$ & $\begin{array}{l}\mathrm{R}^{2}=0.21(\mathrm{p}=0.0023) \\
\text { Age } \\
\text { Age* } \mathrm{MSECO}_{2} \text { (rest) } \\
\text { Mean } t \mathrm{I}^{2}(\mathrm{HVPT}) \\
\text { Age*mean } t \text { ( }(\mathrm{HVPT}) \\
\text { Slope } \mathrm{CO}_{2} \text { (HVPT) }\end{array}$ \\
\hline $\mathrm{N} \sigma^{\top}-\mathrm{AD} \sigma^{\top}$ & $\begin{array}{l}\mathrm{R}^{2}=0.26(\mathrm{p}=0.0009) \\
\text { Slope } \mathrm{CO}_{2} \text { (rest) } \\
\text { Pexpin }(\mathrm{HVPT})\end{array}$ & $\begin{array}{l}\mathrm{R}^{2}=0.31(\mathrm{p}=0.0001) \\
\text { Age } \\
\text { MSECO } \\
\text { Mean } t \mathrm{I}^{2} \text { (rest) } \\
\text { AgP }) \\
\text { Slope } \mathrm{CO}_{2} \text { (HVPT) }\end{array}$ \\
\hline
\end{tabular}

$\mathrm{N}$ : normal subjects; $\mathrm{HV}$ : hyperventilators; $\mathrm{AD}$ : patients with anxiety disorders; $Q$ : female; $\sigma$ : male; rest: during rest; HVPT: followig hyperventilation provocation test; Pexpin: endexpiratory pauses; $t \mathrm{I}$ : inspiratory time; $\mathrm{MSECO}_{2}$ : residual standard deviation of $\mathrm{CO}_{2} ; \mathrm{R}^{2}$ : squared canonical correlation coefficient, corresponding to the portion of the total variance of the difference between the two groups which can be attributed to one or more respiratory variables.

Fig. 5 - Mean values of: a) inspiratory time $(t \mathrm{I})$; b) expiratory time $(t \mathrm{E})$; c) tidal volume $(V \mathrm{~T})$; and d) end-tidal $\mathrm{CO}_{2}$ fractional concentration $\left(F \mathrm{ET}, \mathrm{CO}_{2}\right)$ during a $5 \mathrm{~min}$ recovery period following hyperventilation provocation test. Females are indicated by squares and males by circles. Each point corresponds to the mean of a $20 \mathrm{~s}$ period, except for the value of $\mathrm{F}_{\mathrm{ET}, \mathrm{CO}_{2}}$ at time 0 (first recorded breath). For the sake of clarity, standard deviations are not shown.

interactions with the selected breathing variables were 政 hree respiratory variables recorded both at rest and folWhen only the breathing pattern at rest was investiweaker, particularly in males: the most discriminating variables were the slope of $F \mathrm{ET}, \mathrm{CO}_{2}$ in those aged 20-28 corresponding variables in those aged $29-60$ yrs were mean $t$ I and slope of $F \mathrm{ET}, \mathrm{CO}_{2}$ in females $\left(\mathrm{R}^{2}=0.25\right)$, and $\mathrm{MSE}^{1 / 2}$ of $F \mathrm{ET}, \mathrm{CO}_{2}$ in males $\left(\mathrm{R}^{2}=0.08\right)$.

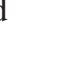



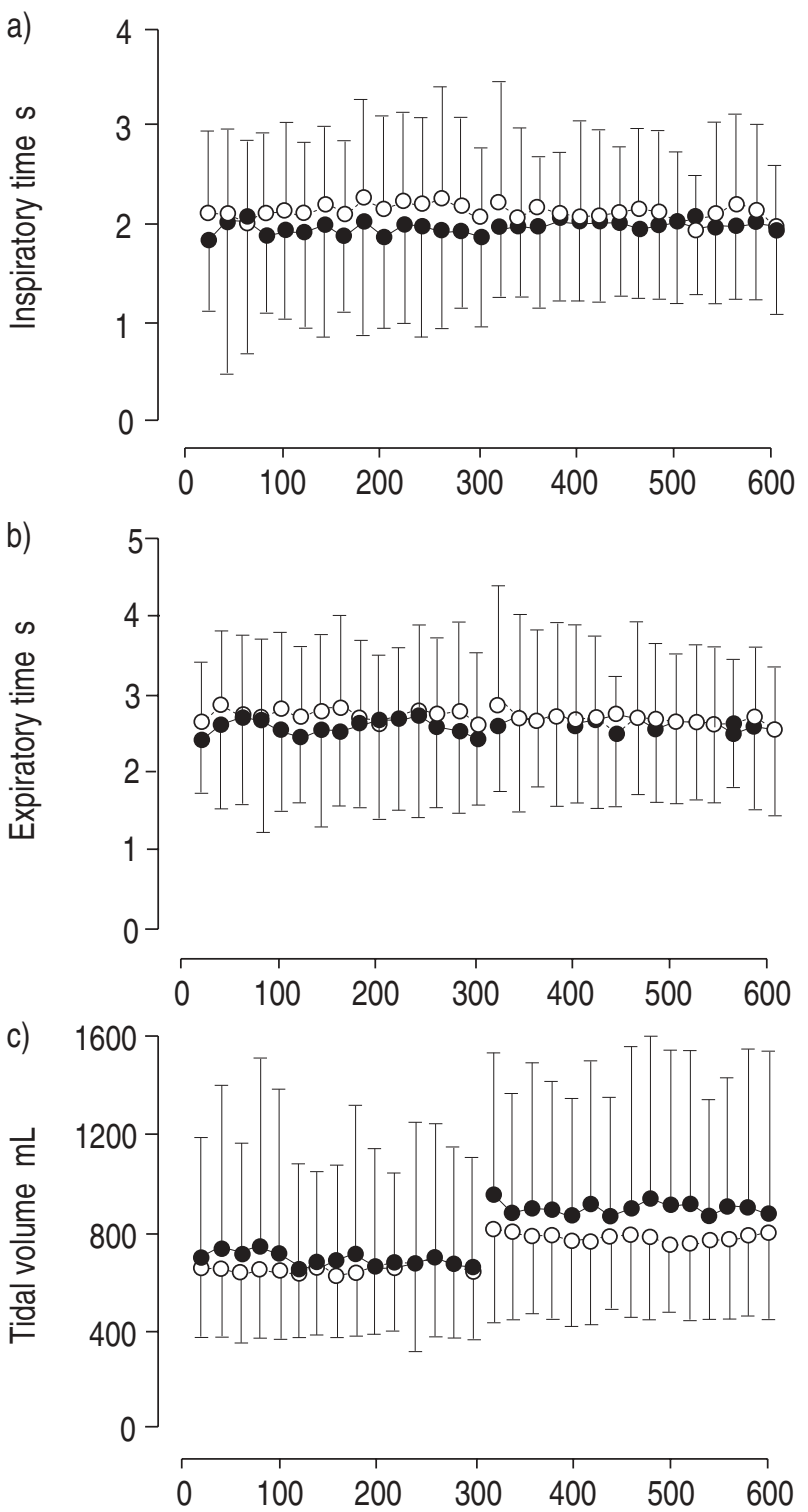

d)

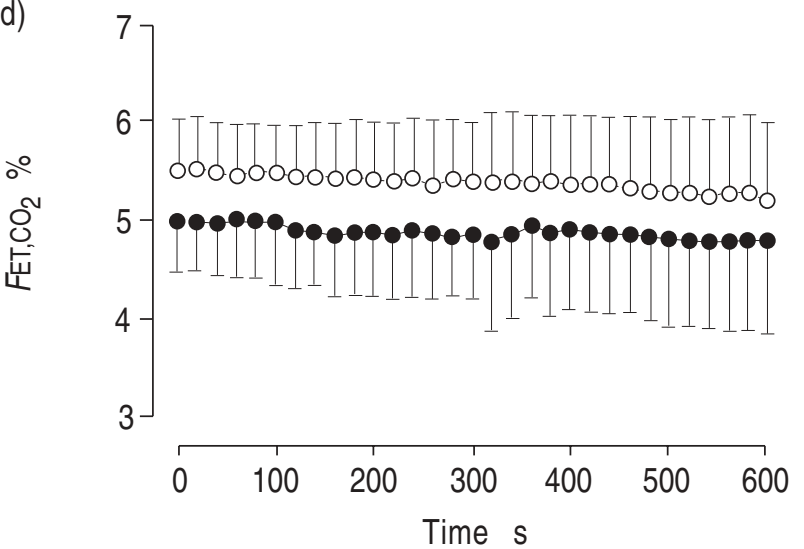

Fig. 6. - Mean values and standard deviation of: a) inspiratory time $(t \mathrm{I})$; b) expiratory time $(t \mathrm{E})$; c) tidal volume $(V \mathrm{~T})$; and d) end-tidal $\mathrm{CO}_{2}$ fractional concentration $\left(F_{\left.\mathrm{ET}, \mathrm{CO}_{2}\right)}\right)$ in 37 normal men (open circles) matched with 37 male hyperventilators (solid circles) during breathing for 5 minutes with Respitrace, followed by 5 minutes breathing simultaneously with pneumotachograph and Respitrace. Each point corresponds to the mean of a $20 \mathrm{~s}$ period, except for the value of $\mathrm{F}_{\mathrm{ET}, \mathrm{CO}_{2}}$ at time 0 (first recorded breath). that in the older age group, patients with HVS tended to breathe faster than normals, both $t \mathrm{I}$ and $t \mathrm{E}$ being reduced $(\mathrm{p}<0.05)$.

Influence of mouthpiece breathing following Respitrace. During breathing via a mouthpiece, $V_{\mathrm{T}}$ increased $(\mathrm{p}<0.001)$, compared with breathing recorded with Respitrace, similarly in hyperventilators and in normal subjects (fig. 6). The within-subject variability of $t \mathrm{I}$ and $t \mathrm{E}$ was less $(\mathrm{p}<$ $0.05)$ compared to breathing with Respitrace. $F \mathrm{ET}, \mathrm{CO}_{2}$ was not influenced. Similar results were obtained in patients with anxiety disorders, and when younger and older subjects were considered separately.

Breathing irregularities. The number of subjects presenting end-expiratory pauses and sighs (over a 5 min period, at least one pause or sigh) was markedly less during breathing through a mouthpiece both in hyperventilators and normal subjects, compared to the number found with Respitrace (table 3 ). Similar results were obtained in patients with anxiety disorders and when younger and older age groups were considered separately. Patients with HVS and anxiety disorders tended to sigh more frequently than normal subjects $(\mathrm{p}<0.05)$.

Discriminant analysis on respiratory parameters during breathing with Respitrace. A discriminant analysis was performed on healthy subjects and hyperventilators (the largest group of patients). The breathing variables introduced into the discriminant function were those derived from the first 5 min breathing with Respitrace (mean value, slope as a function of time, and residual standard deviation of the regression as a function of time for $t \mathrm{I}, t \mathrm{E}, V_{\mathrm{T}}$ and $\left.F \mathrm{ET}, \mathrm{CO}_{2}\right)$. Sighs, end-expiratory pauses and $F \mathrm{ET}, \mathrm{CO}_{2}$ of the first breath were also introduced.

The only discriminating variable was (both for males and females) the FET, $\mathrm{CO}_{2}$ value of the first breath, with $\mathrm{R}^{2}=0.22$ in females $(\mathrm{p}=0.0002)$ and $\mathrm{R}^{2}=0.20$ in males (p=0.0001). Dropping $F_{\mathrm{ET}}, \mathrm{CO}_{2}$ value of the first breath resulted in a replacement of this variable by the mean value of $F \mathrm{ET}, \mathrm{CO}_{2}$ with $\mathrm{R}^{2}=0.18$ in females $(\mathrm{p}=0.001)$ and $\mathrm{R}^{2}=0.21$ in males $(\mathrm{p}=0.0001)$.

Table 3. - Number of subjects who had irregularities during breathing with Respitrace and breathing through mouthpiece

\begin{tabular}{|c|c|c|c|c|}
\hline \multirow[b]{2}{*}{ Irregularities } & \multirow[b]{2}{*}{ Group } & \multirow[b]{2}{*}{$\begin{array}{c}\text { Ss } \\
\mathrm{n}\end{array}$} & \multicolumn{2}{|c|}{ One or more irregularities } \\
\hline & & & Respitrace & Mouthpiece \\
\hline \multirow{4}{*}{$\begin{array}{l}\text { End-expiratory } \\
\text { Pauses }\end{array}$} & $\mathrm{N} \sigma^{7}$ & 37 & 8 & $2 *$ \\
\hline & $\mathrm{HV} \sigma^{\prime}$ & 37 & 7 & $1 * *$ \\
\hline & $\mathrm{N} \varphi$ & 28 & 10 & $1 * *$ \\
\hline & $\mathrm{HV}$ & 28 & 6 & $0 * *$ \\
\hline \multirow{4}{*}{ Sighs } & $\mathrm{N} \sigma^{\top}$ & 37 & $7 \#$ & $3^{\#}$ \\
\hline & $\mathrm{HV} \mathrm{O}^{\top}$ & 37 & 16 & 9 \\
\hline & $\mathrm{N}$ & 28 & 9 & $5 * *$ \\
\hline & $\mathrm{HV}$ & 28 & 14 & $6^{*}$ \\
\hline
\end{tabular}

$\$$ : number of subjects who have one or more irregularities over a period of 5 min breathing at rest. *: $\mathrm{p}<0.05$; **: $<0.01$, significantly less than breathing with Respitrace of the same group; \#: $p<0.05$, significantly less than hyperventilators of the same gender; N: normal subjects; HV: hyperventilators; T : male; $q$ : females; Ss: subjects. 


\section{Discussion}

We investigated whether the breathing pattern in patients with HVS or with anxiety disorders is different from that in healthy subjects. In a first study, we recorded ventilation, by means of a pneumotachograph via a mouthpiece, and $\mathrm{FET}_{\mathrm{ET}} \mathrm{CO}_{2}$, before and after performance of a 3 min period of voluntary hyperventilation (HVPT). Differences varying with age and gender were observed between patients and healthy subjects.

Two age spans were considered: 19-28 and 29-62 yrs; the separation at 28 yrs being determined by the stable breathing pattern between 19-28 yrs (see also [23]) and the sudden reduction of end-expiratory pauses (following HVPT) past that age in healthy subjects (fig. 1).

In patients aged $\leq 28$ yrs (both hyperventilators and patients with anxiety disorders), the striking feature of the breathing pattern at rest was the progressive decline of $F \mathrm{ET}, \mathrm{CO}_{2}$, which started from the onset of the recording, the value at the start of the measurement being similar to that observed in healthy subjects. This progressive decrease of $F_{\mathrm{ET}}, \mathrm{CO}_{2}$ resulted from a higher value of $V_{\mathrm{T}}$ (mainly in males). This hyperventilation progressed towards a steady state in most patients; generally the steady state was not achieved at the end of the 5 min period. These findings are in keeping with those of VANSTEENKISTE et al. [24], who observed that in patients with HVS, breathing via a mouthpiece was regularly accompanied by a progressive decline of $F_{\mathrm{ET}}, \mathrm{CO}_{2}$ of $\geq 0.25 \%$, over a $5 \mathrm{~min}$ period.

The slow recovery of ventilation following voluntary hyperventilation, previously described by HARDONK and BEUMER [13] in HVS, was confirmed in the present study: in the patients aged $\leq 28$ yrs the recuperation of $F \mathrm{ET}, \mathrm{CO}_{2}$ was delayed due to a slower normalization of $t \mathrm{I}$ in women, of $V_{\mathrm{T}}$ in males, and also due to less frequent pauses at the end of expiration.

In patients aged $\geq 29 \mathrm{yrs}$, the striking feature of the breathing pattern at rest as well as following HVPT was the higher respiratory frequency (both $t \mathrm{I}$ and $t \mathrm{E}$ ), specifically in females. The progressive decline of $F \mathrm{ET}, \mathrm{CO}_{2}$ at rest which typified the younger patients, though still present, was less obvious in older patients as compared to healthy subjects of similar age, because the latter presented a similar, though less marked, decline of $F_{\mathrm{ET}}, \mathrm{CO}_{2}$. Following HVPT, the slow recovery of ventilation was still present in patients, especially in males.

End-expiratory pauses reappeared within the first 2 min following cessation of voluntary hyperventilation in healthy subjects. They were exceptional in HVS patients during the $5 \mathrm{~min}$ of posthyperventilation period. Both the recovery of ventilation and the number of pauses following active hyperventilation are controlled by a central neuronal mechanism, potentiating the respiratory response to the same continuing input, and preventing the apnoeas expected on the basis of reduced chemical humoral stimulation (after-discharge phenomenon). This activity results in a continuing but slowly decaying stimulation of respiration [25, 26]. MANGIN et al. [27] pointed out that the number of posthyperventilation end-expiratory pauses is closely related to the degree of vigilance. The latter is probably higher in patients with HVS, owing to their high anxiety level (table 1).

Similarly, the hyperventilation induced by breathing through a mouthpiece, suggests that the respiratory control system is less steady in patients with HVS or anxiety disorders. The reticular activating system acts as a regulating system, ensuring the stability of the breathing pattern in the presence of fluctuations of chemical humoral stimulation [28]. The breathing instability observed in patients might be the result of an overactivity of this system.

We wondered whether this unsteadiness resulted from the use of a mouthpiece. Therefore, we compared the breathing pattern at rest recorded with a mouthpiece and pneumotachograph with that registered by a Respitrace. The breathing was more irregular with the Respitrace: the number of sighs and of end-expiratory pauses, and the within-subjects variability of $t_{\mathrm{I}}$ and $t \mathrm{E}$ decreased markedly during mouthpiece breathing. This is in agreement with the results of GARSSEN and RIJKEN [11] and of ToBin et al. [12]. On the other hand, the progressive decline of $F \mathrm{ET}, \mathrm{CO}_{2}$ starting from an initially normal value, observed in patients during mouthpiece breathing, was not observed during Respitrace recording nor during the following period of mouthpiece breathing: from the onset, $F \mathrm{ET}, \mathrm{CO}_{2}$ was lower than in normal subjects and did not vary significantly during the recordings. Taking in the mouthpiece resulted, as expected [29], in an increase in $V \mathrm{~T}$, similar in normal subjects and in patients, however without modification of $F \mathrm{ET}, \mathrm{CO}_{2}$. Apparently, when preceded by a period of breathing recording by the Respitrace, the mouthpiece did not represent any further challenge for the patients. Actually, the modification of breathing resulting in a decrease of $\mathrm{FET}_{\mathrm{ET}} \mathrm{CO}_{2}$, observed in patients, was already completed when the measurements with Respitrace were started. We submit that the period of breathing unsteadiness responsible for the decrease in $\mathrm{FET}, \mathrm{CO}_{2}$ had taken place prior to the measurements, during the fairly long time interval required for adjusting the measuring device to the subject when using the Respitrace. A lower mean $F_{\mathrm{ET}}, \mathrm{CO}_{2}$ value is frequently mentioned in the literature as a characteristic of HVS [15, 30, 31]. We suggest that the subjects studied by others were in a postchallenge steady state, e.g. because the recording time was prolonged and the first minutes of recording were discarded. This masks the unsteadiness of $F \mathrm{ET}, \mathrm{CO}_{2}$ which we found to be characteristic for HVS and anxiety disorders, and which seems to result from the mere recording of breathing.

Can these features of breathing pattern be used for diagnosis? Table 2 shows that $21-32 \%$ of the differences in breathing during rest and following HVPT are linked to the diagnosis. Though highly significant, the differences in breathing pattern recorded with a mouthpiece do not, therefore, allow for individual diagnosis on the basis of breathing pattern only. The discriminative power of lower $F \mathrm{ET}, \mathrm{CO}_{2}$ values observed when breathing is recorded at rest with a Respitrace is no better.

The patients in the present study (hyperventilators and patients with anxiety disorders) were diagnosed on different bases. However, the breathing pattern of patients with anxiety and HVS is similar. This is in keeping with a recent study of SPINHOVEN et al. [32], and cannot be explained by the large overlap observed between the two diagnoses: patients with HVS only (without anxiety disorders) and with anxiety disorders only (without HVS) demonstrate a similar breathing pattern. In view 
of these results, one might wonder whether it is useful to keep these two diagnostic classifications as separate entities. The diagnostic overlap is not perfect: among the patients with HVS, $17 \%$ of females and $30 \%$ of males presented one or more variants of somatoform disorders, without anxiety disorders, and 3-5\% suffered from depression or dysthymia in the absence of an anxiety or somatoform disorder. On the other hand, among the patients with anxiety disorders, besides those with clearcut HVS ( $65 \%$ of females, $58 \%$ of males), 16 and $13 \%$, respectively, of females and males did not qualify at all for the clinical diagnosis of HVS. In addition, people with HVS only scored significantly higher on the Nijmegen Questionnaire than the patients with anxiety disorders only, whereas the anxiety levels (STAI) were not markedly different. Apparently, HVS is a syndrome straddling both anxiety and somatoform disorders, and characterized by a high level of anxiety, numerous psychological and somatic complaints (feeling tense, palpitations, dyspnoea, thoracic pain, dizziness, fatigue) and a peculiar breathing pattern. In a laboratory environment, a frank hyperventilation is, as a rule, not a feature of the syndrome. This is in agreement with the results of others $[5,13,33]$.

\section{References}

1. Da Costa JM. On irritable heart: a clinical study of a form of functional cardiac disorder and its consequences. Am J Med Sci 1871; 61: 17-52.

2. Lewis T. Report on neurocirculatory asthenia and its treatment. Milit Surg 1918; 42: 408-426.

3 . Freud S. The justification for detaching from neurasthenia a particular syndrome: the anxiety neurosis. Collected papers. Vol 1. London, Hogarth Press, 1950; pp. 76-127.

4. Friedman M. Functional Cardiovascular Disease. Baltimore, The Williams and Wilkins Company 1947; 1-266.

5. Bülow K. Lung function in cardiac neurosis. Acta Med Scand 1961; 169: 1-15.

6. Kerr WJ, Dalton JW, Gliebe PA. Some physical phenomena associated with the anxiety states and their relation to hyperventilation. Ann Intern Med 1937; 11: 961-992.

7. Christie RV. Some types of respiration in the neuroses. Q J Med 1935; 4: 427-434.

8. Kimura E, Takahashi K, Ichikawa A, Kusachi N. Abnormal respiration and unusual movements of the diaphragm in patients with neurocirculatory asthenia. Am J Med Sci 1973; 265: 205-214.

9. Lum LC. Hyperventilation: the tip and the iceberg. $J$ Psychosom Res 1975; 19: 375-383.

10. Hormbrey J, Jacobi MS, Patil CP, Saunders KB. $\mathrm{CO}_{2}$ response and pattern of breathing in patients with symptomatic hyperventilation, compared to asthmatic and normal subjects. Eur Respir J 1988; 1: 846-852.

11. Garssen B, Rijken H. Clinical aspects and treatment of the hyperventilation syndrome. Behav Psychother 1986; 14: 46-68.

12. Tobin MJ, Chadha TS, Jenouri G, Birch SJ, Gazeroglu HB, Sackner MA. Breathing patterns. 2. Diseased subjects. Chest 1983; 84: 286-294.

13. Hardonk HJ, Beumer HM. Hyperventilation syndrome. In: Vinken PJ, Bruyn GW, eds. Handbook of Clinical Neurology. Vol. 38. Neurological Manifestations of System Disease. Part 1. Amsterdam, North Holland Publ., 1979; pp. 309-360.
14. Folgering H, Durlinger M. Time course of posthyperventilation breathing in humans depends on alveolar $\mathrm{CO}_{2}$ tension. J Appl Physiol: Respirat Environ Exercise Physiol 1983; 54: 809-813.

15. Folgering H, Colla P. Some anomalies in the control of $P \mathrm{~A}, \mathrm{CO}_{2}$ in patients with a hyperventilation syndrome. Bull Eur Physiopathol Respir 1978; 14: 503-512.

16. American Psychiatric Association: Diagnostic and statistical manual of mental disorders. 3rd edn (revised). Washington DC, American Psychiatric Association, 1987.

17. Van Dixhoorn J, Duivenvoorden HJ. Efficacy of Nijmegen Questionnaire in recognition of the hyperventilation syndrome. J Psychosom Res 1985; 29: 199-206.

18. Dinardo PA, O'Brien GT, Barlow DH, Waddell MT, Blanchard EB. Reliability of DSM-III anxiety disorder categories using a new structured interview. Arch Gen Psychiat 1983; 40: 1070-1074.

19. Van der Ploeg HM, Defares PB, Spielberger CD. Handleiding bij de Zelfbeoordelingsvragenlijst ZBV: een nederlandstalige bewerking van de Spielberger State-Trait Anxiety Inventory STAI-DY. Lisse, Swets \& Zeitlinger, 1979.

20. Spielberger CD, Gorsuch RL, Luchene RE. The StateTrait Anxiety Inventory (STAI) test manual for form X. Palo Alto, CA, Consulting Psychologist Press, 1970.

21. Strömberg NOT, Dahlbäck GO, Gustafsson PM. Evaluation of various models for respiratory inductance plethysmography calibration. J Appl Physiol 1993; 74: 1206-1211.

22. Loveridge B, West P, Anthonisen NR, Kryger MH. Single-position calibration of the respiratory inductance plethysmograph. J Appl Physiol: Respirat Environ Exercise Physiol 1983; 55: 1031-1034.

23. Jammes Y, Auran Y, Gouvernet J, Delpierre S, Grimaud C. The ventilatory pattern of conscious man according to age and morphology. Bull Eur Physiopathol Respir 1979; 15: 527-540.

24. Vansteenkiste J, Rochette F, Demedts M. Diagnostic tests of hyperventilation syndrome. Eur Respir J 1991; 4: 393-399.

25. Eldridge FL, Chen Z. Respiratory sensation. A neurophysiological perspective. In: Adams L, Guz A, eds. Respiratory Sensation. New York, Marcel Dekker Inc., 1996; pp. 19-67.

26. Eldridge FL, Gill-Kumar P. Central neural respiratory drive and after-discharge. Respir Physiol 1980; 40: 49-63.

27. Mangin P, Krieger J, Kurtz D. Apnea following hyperventilation in man. $J$ Neurol Sci 1982; 57: 67-82.

28. Plum F, Brown HW. The effect on respiration of central nervous system disease. Ann NY Acad Sci 1963; 109: 915-930.

29. Gilbert R, Auchincloss JH, Brodsky JJ, Boden W. Changes in tidal volume, frequency and ventilation induced by their measurement. J Appl Physiol 1972; 33: 252-254.

30. Gardner WN, Meah MS, Bass C. Controlled study of respiratory responses during prolonged measurement in patients with chronic hyperventilation. Lancet 1986; ii: 826-830.

31. Freeman LJ, Conway A, Nixon PGF. Physiological responses to psychological challenge under hypnosis in patients considered to have the hyperventilation syndrome: implications for diagnosis and therapy. $J R S o c$ Med 1986; 79: 76-83.

32. Spinhoven PH, Onstein EJ, Sterk PJ, Le Haen-Versteijnen D. Discordance between symptom and physiological criteria for the hyperventilation syndrome. J Psychosom Res 1993; 37: 281-289.

33. Lum LC. Hyperventilation syndromes in medicine and psychiatry: a review. J R Soc Med 1987; 80: 229-231. 